\title{
The Comparative Effect of Teaching Spelling through Mnemonics and Phonics on EFL Learners' Vocabulary Achievement and Retention
}

\author{
Mona Khabiri \\ Islamic Azad University, Central Tehran Branch, Iran \\ Roqayeh Rezagholizadeh \\ Islamic Azad University, Central Tehran Branch, Iran
}

\begin{abstract}
The purpose of present study was to examine the comparative effect of teaching spelling through mnemonics and phonics on EFL learners' vocabulary achievement and retention. Sixty female students of a junior high school were chosen among one hundred elementary students. To ensure the homogeneity of the students, a Key English Test was administered to all one hundred students, and a teacher-made vocabulary test was piloted with 30 students with similar characteristics to the target participants.The sixty students were divided randomly into two experimental groups, each group contains thirty students, the students in experimental group one were instructed mnemonics and the other experimental group were instructed phonics. Before treatment the teacher-made vocabulary test was administered as a pre - test and after the treatment post- test was run two times, first for vocabulary achievement, and after two weeks for retention. The design was quasi experimental. The results of the RM ANOVA indicated that there was no significant difference between the effect of phonics and mnemonics on EFL learners' vocabulary achievement, nor was there any significant difference between the effect of the two treatments on their vocabulary retention.
\end{abstract}

Index Terms — spelling, mnemonics, phonics, vocabulary achievement, vocabulary retention

\section{INTRODUCTION}

Many students struggle throughout their educational career with learning how to spell (McLaughlin, Weber, \& Barretto, 2004; Nies \& Belfiore, 2006; Templeton, 1986). When students learn to spell, they must learn to correctly encode a word into the written form. One of the reasons that spelling is difficult for students of English is that the correspondence between the sound of a word and the way it is spelt is not always obvious. Mnemonics and phonics are two techniques for teaching spelling.

Mnemonics are techniques or devices such as a rhyme or an image that serves to enhance the storage and the recall of information contained in memory (Solso, 1995, p. 257).Another technique for teaching spelling is phonics. It is the systematic teaching of the sounds conveyed by letters and groups of letters and includes teaching children to combine and blend these to read or write words (Bald, 2007, p. 1).

Vocabulary is an important element in language (Hoshino, 2010) and a necessary component for improving competency in all areas of communication (Godwin-Jones, 2010). Vocabulary knowledge plays a critical role in people's lives and future possibilities (Beck, McKeown, \& Kucan, 2002). In fact, "it is clear that a large and rich vocabulary is the hallmark of an educated individual. A large vocabulary repertoire facilitates becoming an educated person to the extent that vocabulary is strongly related to reading comprehension in particular and school achievement in general" (Beck et al., p. 1).

Meanwhile Mohammed (2009, p. 16) defines vocabulary retention as "the ability to keep the acquired vocabulary and retrieve it after a period of time to use it in different language contexts".

\section{A. Statement of the Problem}

There is no doubt that vocabulary is central to language learning and of critical importance to language learners (Zimmerman, 1997).

Although phonics as one of the variables of the study does not cause fluency, it does contribute to fluency through its effect on vocabulary (Eldredge, 2005).

As a teacher the researcher has observed that the students in Iran have problems in learning and recalling the new words. For example, when they look up the meaning of a word in a dictionary, they do not pay attention to the parts of speech, word origins, and example sentences. Consequently, they cannot use those words appropriately and as the result 
forget them easily. Moreover, they ignore the pronunciation of the new words they learn. So, they mispronounce the words; which in turn, obstructs the ability to remember the new words.

Consequently considering the students' need for vocabulary learning and their interest in adopting effective techniques for learning new words as well as the challenge they face in learning English spelling system, the purpose of the present study was to examine the comparative effect of teaching spelling through mnemonics and phonics on EFL learners' vocabulary achievement and retention.

\section{B. Statement of the Research Questions}

This study aims to answer the following questions:

$Q_{1}$. Is there any significant difference between the effect of teaching spelling through Mnemonics and Phonics on EFL learners' vocabulary achievement?

$Q_{2}$. Is there any significant difference between the effect of teaching spelling through Mnemonics and Phonics on EFL learners' vocabulary retention?

\section{REVIEW OF THE LITERATURE}

Among phonics teaching methods, two major approaches to phonics instruction, synthetic and analytic, are widely discussed (Blevins, 1998; Dakin, 1999; Gunning, 1996).

\section{A. Synthetic Phonics Approach}

Synthetic phonics, also referred to as direct or explicit phonics, builds from part to whole (Dakin, 1999). This method follows a bottom-up model of learning to read (Blevins, 2006, p.111).Synthetic phonics is a way of teaching children to read. The word 'synthetic' reflects the practice of 'synthesizing' or blending together.

\section{B. Analytic Phonics Approach}

Analytic phonics is a form of phonics in which sounds are not taught in isolation and individual units as those in synthetic phonics, but are taught within the context of known and familiar words (Cunningham, 2000). So, it is also known as indirect or implicit phonics.

\section{Mnemonics}

According to Thompson (1987), [M]mnemonics work by utilizing some well-known principles of psychology: a retrieval plan is developed during encoding, and mental imagery, both visual and verbal, is used. They help individuals learn faster and recall better because they aid the integration of new material into existing cognitive units and because they provide retrieval cues (p. 211).

\section{Mnemonic Techniques}

\section{Peg Word Method}

The peg word mnemonic technique consists of two steps. Inthe first step, the learner remembers the rhyming words for the number 1 to 10 . In thesecond step, the learner visualizes the new word and the rhyming word and thenassociates these two things with other words with the related number (McCabe,2010).

\section{Loci Method}

According to Nemati (2009), "to use this ancient technique,imagine a familiar location such as a room, then mentally place items to beremembered there, to recall take an imaginary walk along the landmarks in the roomand retrieve the items in it" (p. 124). Bakken and Simpson (2011) also note that theloci method or mental walk can be performed through imaginations and pictures to organize and remember information.

\section{The key word method}

The keyword method is a mnemonic strategy for learning foreign-English pairs. This technique is conducted in such a manner that connects the foreign word to a keyword. The Keyword is a concrete English word which has some similarity in sound to some part of the foreign word. Afterwards, the learner creates a memorable mental image of the keyword to the English equivalent (translation) to show their interactions (Crutcher, 1990). The keyword mnemonic strategy facilitates learning and remembering complex information. The keyword method uses the visualization of information to determine its meanings and suggests more than the ordinary information (Keskinkilic \& Sunbul, 2011).

\section{Acrostics}

Acrostics support recall by creating an entire sentencewith the first letter of each word to be remembered.For example, the names of the lines in the treble clefcorrespond to the first letter of each word in the sen-tence "Every good boy deserves fudge." Similarly,Mastropieri and Scruggs (1991) suggested the sen-tence "George's elderly old grandfather rode a pighome yesterday" to recall the spelling for the word"geography.

\section{Acronyms}

Basedon Oxford (1990) using acronyms is a kind of placing newwords into a context in order to remember them better.Placing new language information to concepts in memoryby means of meaning visual imagery either in the mind orin an actual drawing is called using imagery. 


\section{MethodOLOGY}

\section{A. Participants}

The participants of the study were sixty students with the age range of 13 to 14 . They were female students of a public junior high school in Tehran that were chosen from a non-randomly selected sample of one hundred elementary students. In order to ensure the homogeneity of the students, a Key English Test (KET) was administered to all the one hundred students. Seventy students whose scores were one standard deviation above and below the sample mean were selected as the target participants for the study.

Then the 70 homogenized participants took the vocabulary test which consisted of the target vocabularies and 10 participants who knew even one of the vocabularies were omitted from the sample. The remaining 60 participants were divided randomly into two experimental groups, each group containing thirty students. In one group spelling was taught through mnemonic and in the other, it was taught through phonics.

The KET was piloted with 30 other elementary students who had almost the same characteristics of the target sample. The researcher used the results to conduct item analysis and measure reliability of the test which was later used for homogenizing the main participants of the study.

It is worth to mention that the vocabulary test was also piloted with 30 elementary students at another high school before the main phase of the study for the selection of the vocabularies suitable for the purpose of the study. A 60 multiple-choice vocabulary test, which was developed by the researcher, with a list of 100 vocabularies was given to 30 students who were at the same age and grade but were not the target participants nor the ones who took part in the pilot study of KET. In this pilot study the issues regarding the administration, time allocation, clarity of test rubric, appropriacy of the language of input, and other issues were also surveyed and necessary changes were made to the test.

\section{B. Procedure}

To conduct this research, initial KET was piloted with 30 elementary students who shared similar characteristics with the target participants. This was done in order to conduct item analysis and measure reliability of the test. As the result of the pilot study, malfunctioning items including three listening and seven reading and writing items were omitted. After piloting KET, the 60-item teacher-made vocabulary test with a list of 100 vocabularies was administered to the other pilot group to find out which vocabularies were known to the learners and thus omit them from the posttest and delayed posttest. Ten familiar vocabularies were discarded.

The treatment was carried out in 16 sessions, each lasting 30 to 45 minutes. Classes were held twice in a week. During these sessions 82 vocabularies were taught. Five vocabularies were taught in each session except for two sessions in which six vocabularies were taught. The researcher herself taught the two experimental groups. The groups had the same condition in terms of hours of instruction, number of vocabularies, and text book. The only difference was the teaching method. At the end of the treatment both groups took part in the vocabulary posttest. Note that the students were not told that they were supposed to take part in a subsequent test to measure their vocabulary retention. After two weeks, the participants of both groups took the same vocabulary test as the delayed posttest to demonstrate their vocabulary retention. In the following sections the particular treatment that was conducted in each group is explained.

\section{Mnemonics Group}

The researcher taught spelling through mnemonics to this group. In the mnemonics group, in each session the researcher taught five words through mnemonic techniques.

1. Listing the vocabularies on the board and explaining their meaning either through definition, examples, translation, or drawing using flashcards, different pictures, multimedia, etc.

2. Using key word as one kind of mnemonics:

3. Asking pupils to do the activities in the pupil's worksheets individually, in pairs or in groups.

4. Using acrostics as one kind of mnemonics.

5. Using acronyms as one kind of mnemonics.

6. Using rhyming and Catching phrases

7. The teacher showed pictures or different sentences till they recognized the meanings.

8. In addition the students practiced some other target words through peg word method.

\section{Phonics Group}

In the phonics group, just like the mnemonic group, in each session the researcher taught five words through Phonics. The teacher categorized the vocabularies into nouns, verbs, adjectives, adverbs, and prepositions. She taught the students the number of syllables each had. That is, she explained whether the words were monosyllabic, disyllabic, or tri-syllabic, etc.

To do so, the teacher needed to introduce some concepts such as 'syllable' and the fact that each syllable contains one vowel sound and one or more consonant sounds (giving examples such as: 'Begin' has two syllables, /be/ and /gin/); 'Vowel' and the fact that each vowel can make a long sound (its own name) or a short sound; 'Consonant'; 'Digraphs' (giving examples of consonant and vowel digraphs). 
The researcher used two approaches. In synthetic phonics, she segmented the words and then blended them and in analytic phonics she drew their attention to the rhyme and the onset rather than the words in isolation..

\section{RESULTS AND DISCUSSION}

The results of the RM ANOVA indicated that there was no significant difference between the effect of phonics and mnemonics on EFL learners' vocabulary achievement, nor was there any significant difference between the effect of the two treatments on their vocabulary retention. The researcher was thus unable to reject the two null hypotheses of the study. However, both groups proved to have significant improvement from the posttest to the delayed posttest indicating that each group demonstrated retention which of course was not significantly different from the other group.

Since the vocabulary test was an achievement test and thus, a Criterion-Referenced Test (CRT), the reliability of the posttest and delayed posttest were computed based on CRT approaches which is called dependability of the test. Table 5 shows the dependability of the vocabulary posttest and delayed posttest of the Phonics and Mnemonic groups.

TABLE 4.1.

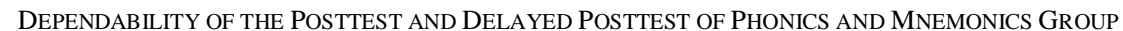

\begin{tabular}{|l|l|l|l|l|}
\hline & $\alpha$ Reliability & Z score & Kappa Coefficient & Agreement Coefficient \\
\hline Mnemonic Posttest & .903 & .29 & .71 & .86 \\
\hline Phonics Posttest & .914 & .21 & .71 & .86 \\
\hline Mnemonic Delayed Posttest & .919 & .14 & .71 & .86 \\
\hline Phonics Delayed Posttest & .920 & -.01 & .71 & .86 \\
\hline
\end{tabular}

TABLE 4.2

DesCRIPTIVE STATISTICS OF THE POSTTEST OF THE PHONICS AND MNEMONICS GROUPS

\begin{tabular}{|c|c|c|c|c|c|c|c|}
\hline & \multirow{2}{*}{$\begin{array}{l}\mathrm{N} \\
\text { Statistic }\end{array}$} & \multicolumn{2}{|l|}{ Mean } & \multirow{2}{*}{$\begin{array}{l}\text { Std. Deviation } \\
\text { Statistic } \\
\end{array}$} & \multicolumn{3}{|c|}{ Skewness } \\
\hline & & Statistic & Std. Error & & Statistic & Std. Error & Ratio \\
\hline Phonics Posttest & 30 & 18.93 & 1.33 & 7.31 & -.169 & .427 & -.395 \\
\hline Mnemonic Posttest & 30 & 18.47 & 1.27 & 6.99 & .181 & .427 & .423 \\
\hline Valid N (listwise) & 60 & & & & & & \\
\hline
\end{tabular}

As demonstrated, the mean of the Phonics and Mnemonic group turned out to be 18.93 and 18.47 respectively. The descriptive statistics of the delayed posttest was also computed for the two groups, which is represented in Table 3.

TABLE 4.3.

Descriptive Statistics of THE Delayed POSTTEST OF PHONICS AND MNEMONIC GROUP

\begin{tabular}{|l|l|l|l|l|l|l|l|}
\hline & N & Mean & Std. Deviation & \multicolumn{2}{l|}{ Skewness } \\
\cline { 2 - 8 } & Statistic & Statistic & Std. Error & Statistic & Statistic & Std. Error \\
\hline Phonics Delayed Posttest & 30 & 20.6 & 1.3 & 7.11 & -.507 & .427 \\
Mnemonic Delayed Posttest & 30 & 19.50 & 1.33 & 7.27 & .016 & .427 \\
Valid N (listwise) & 60 & & & & & & \\
\hline
\end{tabular}

Table 4.3 illustrates that the Phonics group obtained a higher mean (20.6) as compared to that of the Mnemonic group (19.5).

To verify the null hypothesis that stated There is no significant difference between the effect of teaching spelling through Mnemonics and Phonics on EFL learners' vocabulary achievement, and the one which stated There is no significant difference between the effect of teaching spelling through Mnemonics and Phonics on EFL learners' vocabulary retention, the researcher had to conduct a Repeated Measures ANOVA to compare the results of the posttest and the delayed posttest of the two groups.

Prior to this, the normality of the distribution of these scores within each group was checked.

TABLE 4.4

LEVENE'S TEST OF EQUALITY OF ERROR VARIANCES ${ }^{\mathrm{A}}$

\begin{tabular}{|l|l|l|l|l|}
\hline & F & df1 & df2 & Sig. \\
\hline Posttest & .104 & 1 & 58 & .748 \\
Delayed Posttest & .156 & 1 & 58 & .695 \\
\hline
\end{tabular}

According to Table 4.4 the results of the Levene's test demonstrated that the assumption of equal variance was maintained for the posttest scores $(\mathrm{F}=.104, p=.748)$ as well as the delayed posttest scores $(\mathrm{F}=.156, p=.695)$. Therefore, running RM ANOVA was legitimized.

Results shows that no significant difference was found between the two groups $(\mathrm{F}=.195, \mathrm{df}=1,58, p=.661>.05$, partial Eta Squared=.003). This indicates that a significant difference could be found neither between the posttest 
results nor between the delayed posttest results of the Phonics and Mnemonics group. So, neither the first nor the second null hypothesis could be rejected.

This study examined the comparative effect of teaching spelling through phonics and mnemonics on EFL learners' vocabulary achievement and retention. The results of the RM ANOVA indicated that there was no significant difference between the effect of phonics and mnemonics on EFL learners' vocabulary achievement, nor was there any significant difference between the effect of the two treatments on their vocabulary retention. The researcher was thus unable to reject the two null hypotheses of the study. However, both groups proved to have significant improvement from the posttest to the delayed posttest indicating that each group demonstrated retention which of course was not significantly different from the other group.

There may be few justifications for the findings of this study. One is that although the researcher taught vocabulary through mnemonics and phonics, some of the participants in both groups learned to mix these methods with the previous methods they had been exposed to and which they had rotely learned resulting in a kind of intervening variable (previous methods) which may have camouflaged the effect of each method. The other reason may be the time limitation, meaning that over a longer span of time the students may overcome their involvement with the previously methods of practicing vocabulary and thus respond to the phonics and mnemonics methods differently.

The fact that in this study no significant difference was not found between mnemonics and phonics on vocabulary achievement and retention of the learners, might have been due to the difference between the features of the participants of the current study with those of the studies mentioned above. The participants of this study had prior familiarity with phonics through the spelling part of their exams in which they used to spell the words (segmented and blended them), but had no such acquaintance with mnemonics. This fact might have even influenced their motivation to effectively involve in the practice during the treatment.

\section{SUMMARY OF FINDINGS AND CONCLUSION}

In order to compare the effect of the two treatment, the results of the posttest and delayed posttest of the two groups were put to statistical analysis through Repeated Measures ANOVA. The results indicated equal variance for the posttest scores $(\mathrm{F}=.104, p=.748)$ as well as the delayed posttest scores $(\mathrm{F}=.156, p=.695)$. Therefore, running $\mathrm{RM}$ ANOVA was legitimized and the results of the covariances bore no significance $(\mathrm{M}=3.023, p=.406)$.

In addition the within-subject factor was inserted for the RM ANOVA and the results showed that the effect of factor 1 was significant $(\mathrm{F}=6.461, p=.014<.05)$. This indicated that there was a significant difference between the posttest and the delayed posttest of each group. That is, each group had a better retention compared to their achievement which was of course not the focus of the study. The focus of the study was to compare the achievement and the retention of the two groups.

Moreover the interaction between factor 1 and Group turned out to be insignificant $(\mathrm{F}=.353, p=.553>.05)$ and tests of between-subjects effects showed that no significant difference was found between the two groups $(\mathrm{F}=.195, \mathrm{df}=1,58$, $p=.661>.05$, partial Eta Squared=.003). This indicated that a significant difference could be found neither between the posttest results nor between the delayed posttest results of the Phonics and Mnemonics group. As the result, neither the first nor the second null hypothesis could be rejected.

In the feedback the students provided throughout the treatment, the students in the Phonics group stated that it was easy for them to learn phonics patterns and they would apply certain phonics rules to learn new words._On the other hand, some of the students in the mnemonic group asserted that they did not like to learn memory strategies and that they were used to memorizing and rote learning. Therefore, in the discussion section, the researcher argued that the familiarity of the participants with the phonics method through their exams might have caused the findings of this study to differ from other similar studies in the literature which had found better results with mnemonics. Therefore, it could be concluded that the familiarity of the participants in the context of this research with phonics method and their unfamiliarity with the mnemonics method might have influenced the findings of this study and consequently yielded no significant difference between the two treatments.

Other reasons were presented in the discussion section in the previous chapter for the difference between the finding of the current study and those in which mnemonics proved to be more effective than phonics; namely the possible role of the previous methods of instruction as intervening variable; the emphasis of phonics method on pronunciation and stress through onset and rhyme that according to the literature can contribute to retention and thus might have neutralized the difference between the two treatments; and finally failing to use one of the most effective techniques in the Mnemonic group, namely key word technique, for the abstract words. Therefore, it can be concluded that certain features of the context of the current research might have resulted in almost equal impact of the two methods of teaching spelling, phonics and mnemonics, on vocabulary achievement and retention of the learners.

Ultimately it can be asserted that despite the findings in the literature one comes to the realization that no single method can cover all aspects of vocabulary learning at the same time nor can it suit all learners with varying levels of achievement. Successful teaching depends on teacher's effort to flexibly apply the most effective approach to meet the students' needs, especially those underachieving ones. In this attempt, familiarity of the students with certain approaches and procedures along with their motivation and desire to welcome new approaches cannot be denied as influential factors. 


\section{REFERENCERS}

[1] Bakken, J.P. \& Simpson, C. G. (2011). Mnemonic strategies: Success for the young-adult learner. The Journal of Human Resource and Adult Learning, 17(2), 79-85.

[2] Bald, J. (2007). Using Phonics to Teach Reading and Spelling. London: Paul Chapman. Retrieved on October 15, 2012,from:http://www.sagepub.com.

[3] Beck, I.L., McKeown, M.G., \& Kucan, L. (2002). Bringing words to life: Robust vocabulary instruction. New York. Retrieved on November 15, 2012, from: http://www.cpin.us.

[4] Blevins, W. (1998). Phonics from A to Z- A practical guide. New York: Scholastic.

[5] Blevins, W. (2006). Phonics from A to Z- A practical guide(2nd ${ }^{\text {ed }}$ ). Scholastic Inc.,557 Broadway, New York ,NY 1002.

[6] Crutcher, R. J. (1990). The role of mediation in knowledge acquisition and retention: Learning foreign vocabulary using the keyword method (ICS Tech. Rep. No. 90-10). University of Coronado: Institute of Cognitive Science.

[7] Cunningham, P. M. (2000). Phonics they use .Words for writing and reading. New York: Addison-Wesley Longman.

[8] Dakin, A. B. (1999). The effectiveness of a skill based explicit phonics reading program K-2 as measured by student performance and teacher evaluation. Retrieved August 5, 2013, from ERIC database (ED 430 215).

[9] Eldredge, J. L. (2005). Foundations of fluency: An exploration. Reading Psychology, 26, 161-181.

[10] Godwin Jones, R. (2010). Emerging technologies, from memory places to spacing algorithms: Approaches to second language vocabulary learning. Language Learning \& Technology, 14, 4-11 .http://www.asiatefl.org/journal.

[11] Gunning, T. G. (1996). Creating reading instruction for all children (2nd ed.). Boston: Allyn and Bacon.

[12] Hoshino, Y. (2010). "The categorical facilitation effects on L2vocabularylearningin a classroom setting", RELC Journal, 41(3), pp. 301-312. Retrieved on October 4, 2012, from: http:// www. journals.usb.ac.ir.

[13] Keskinkiliç, G. \& Sünbül, A. M (2011). The effects of mnemonic keyword method on science lessons: Access and attitude of students. International Journal on New Trends in Education and in their Implications, 2(4), 1-8.

[14] McCabe, J.A. (2010). Integrating mnemonics into psychology instruction. Instructional Resource Award Recipient. Goucher College: Department of Psychology. Retrieved September18, 2012 from http://www.teach psych.org/otrp/resources/mccabe11.pdf

[15] Mastropieri, M. A., \& Scruggs, T. E. (1991). Teaching student's ways to remember. Cambridge, MA: Brookline Books. Retrieved October 3, 2012, from: http://www.cle.osu.edu/lwc-publications.

[16] McLaughlin, T. F., Weber, K. P., \& Barretto, A. (2004). Spelling: Academic interventions. In T.S. Watson \& C. H. Skinner (Eds.), Encyclopedia of school psychology(pp. 317-320). New York: Kluwer Academic/Plenum Publishers.

[17] Mohammed, E.F.(2009).The Effectiveness of TPRS in Vocabulary Acquisition and Retention of EFL Prep. Stage Students and their Attitude towards English Language. Unpublished MA Thesis ,Mansoura University, Egypt.

[18] Nemati, A. (2009). Memory vocabulary learning strategies and long term Retention .International Journal of Vocational and Technical Education, 1(2),014024.

[19] Nies, K. A. \& Belfiore, P. J. (2006).Enhancing spelling performance in students with learning disabilities. Journal of Behavioral Education, 15, 162-170. Retrieved on December 10, 2012, from: http:// www. journals.cec.sped.org.

[20] Oxford, R. L. (1990). Language learning strategies: What every teacher should know. Boston: Heinle \& Heinle Publisher.

[21] Solso, R. L. (1995). Cognitive psychology. Allyn and Bacon: Boston. Retrieved on January 15, 2013, from: http:// www.utas.edu.au.

[22] Templeton, S. (1986). Synthesis of research on the learning and teaching of spelling. Educational Le. Retrieved on January 15 , 2013, from: http:// www.savap.org.pk.

[23] Thompson, G. (1987). Using bilingual dictionaries. ELT Journal, 41, 282-286. Retrieved on January 15, 2013, from: http:// www.eltj.oxfordjournals.org.

[24] Thompson, I. (1987). Memory in language learning. In A. Wenden and J. Rubin (Eds.), Learner strategies in language learning,(43-56). New York: Prentice Hall.

[25] Zimmerman, C. B. (1997). Do reading and interactive vocabulary instruction make a difference? An empirical study. TESOL Quarterly, 31, 121-141. Retrieved on October 10, 2012, from: http:// www.onlinelibrary.wiley.com .

Mona Khabiri is Assistant Professor of Applied Linguistics at Islamic Azad University, Central Tehran Branch and the Director of Journal of English Language Studies (JELS). She mainly teaches language testing, research methodology, seminar in TEFL issues, and teaching language skills at graduate level and her main areas of interest include teacher education, cooperative learning, language testing and research. She has published papers in international and national academic journals and presented in several national and international seminars.

Roqayeh Rezagholizadeh is from Iran. She is an English teacher in High school. She got her MA in TEFL from the Islamic Azad University of Tehran ,Central Branch and her BA in English Literature from Tehran University. Her areas of interest in doing research are teaching and learning language skills. 